\title{
Improving patient care in neurosurgery through postoperative telephone calls: a systematic review and lessons from all surgical specialties
}

\author{
Dylan Goehner, MD, ${ }^{1}$ Sandeep Kandregula, MD, ${ }^{2}$ Harjus Birk, MD, ${ }^{2}$ Christopher P. Carroll, MD, 3,4 \\ Bharat Guthikonda, MD, MBA, ${ }^{2}$ and Jennifer A. Kosty, MD² \\ ${ }^{1}$ University of Massachusetts Medical School, Department of General Surgery, Worcester, Massachusetts; 'Louisiana State \\ University Health Shreveport School of Medicine, Department of Neurosurgery, Shreveport, Louisiana; ${ }^{3}$ Department of Brain \& \\ Spine Surgery, Naval Medical Center, Portsmouth, Virginia; and ${ }^{4}$ Department of Surgery, Division of Neurosurgery, Uniformed \\ Services University, Bethesda, Maryland
}

\begin{abstract}
OBJECTIVE Postoperative telephone calls are a simple intervention that can be used to improve communication with patients, potentially affecting patient safety and satisfaction. Few studies in the neurosurgical literature have examined the effect of a postoperative telephone call on patient outcomes, although several exist across all surgical specialties. The authors performed a systematic review and analyzed studies published since 2000 to assess the effect of a postoperative telephone call or text message on patient safety and satisfaction across all surgical specialties.
\end{abstract}

METHODS A search of PubMed-indexed articles was performed on June 12, 2021, and was narrowed by the inclusion criteria of studies from surgical specialties with $>50$ adult patients published after 1999, in which a postoperative telephone call was made and its effects on safety and satisfaction were assessed. Exclusion criteria included dental, medical, and pediatric specialties; systematic reviews; meta-analyses; and non-English-language articles. Dual review was utilized.

RESULTS Overall, 24 articles met inclusion criteria. The majority reported an increase in patient satisfaction scores after a postoperative telephone call was implemented, and half of the studies demonstrated an improvement in safety or outcomes.

CONCLUSIONS Taken together, these studies demonstrate that implementation of a postoperative telephone call in a neurosurgical practice is a feasible way to enhance patient care. The major limitations of this study were the heterogeneous group of studies and the limited neurosurgery-specific studies.

https://thejns.org/doi/abs/10.3171/2021.8.FOCUS21410

KEYWORDS telephone call; postoperative follow-up; patient satisfaction

$\mathrm{P}$ ATIENT satisfaction and safety outcomes are two commonly assessed quality indicators in the delivery of medical care, and hospital systems and physician groups are continually striving for excellence in these categories. While there are many ways to improve these metrics, increased communication is one simple intervention. This can be achieved with a postoperative telephone call or text message..$^{1-3}$ In postoperative patient care, a simple telephone call can answer any questions or concerns that have arisen since discharge, potentially saving time and healthcare dollars.

There are a limited number of studies in the neurosurgical literature that have evaluated the effect of a post- operative telephone call on patient outcomes; however, other surgical specialties have explored this topic. We conducted a systematic review of all studies published in any surgical specialty exploring the relationship between a postoperative telephone call and patient satisfaction and/or safety.

\section{Methods}

This study was conducted following the guidelines of Preferred Reporting Items for Systematic Reviews and Meta-Analyses (PRISMA) to investigate the role of a postoperative follow-up telephone call or text message. The 


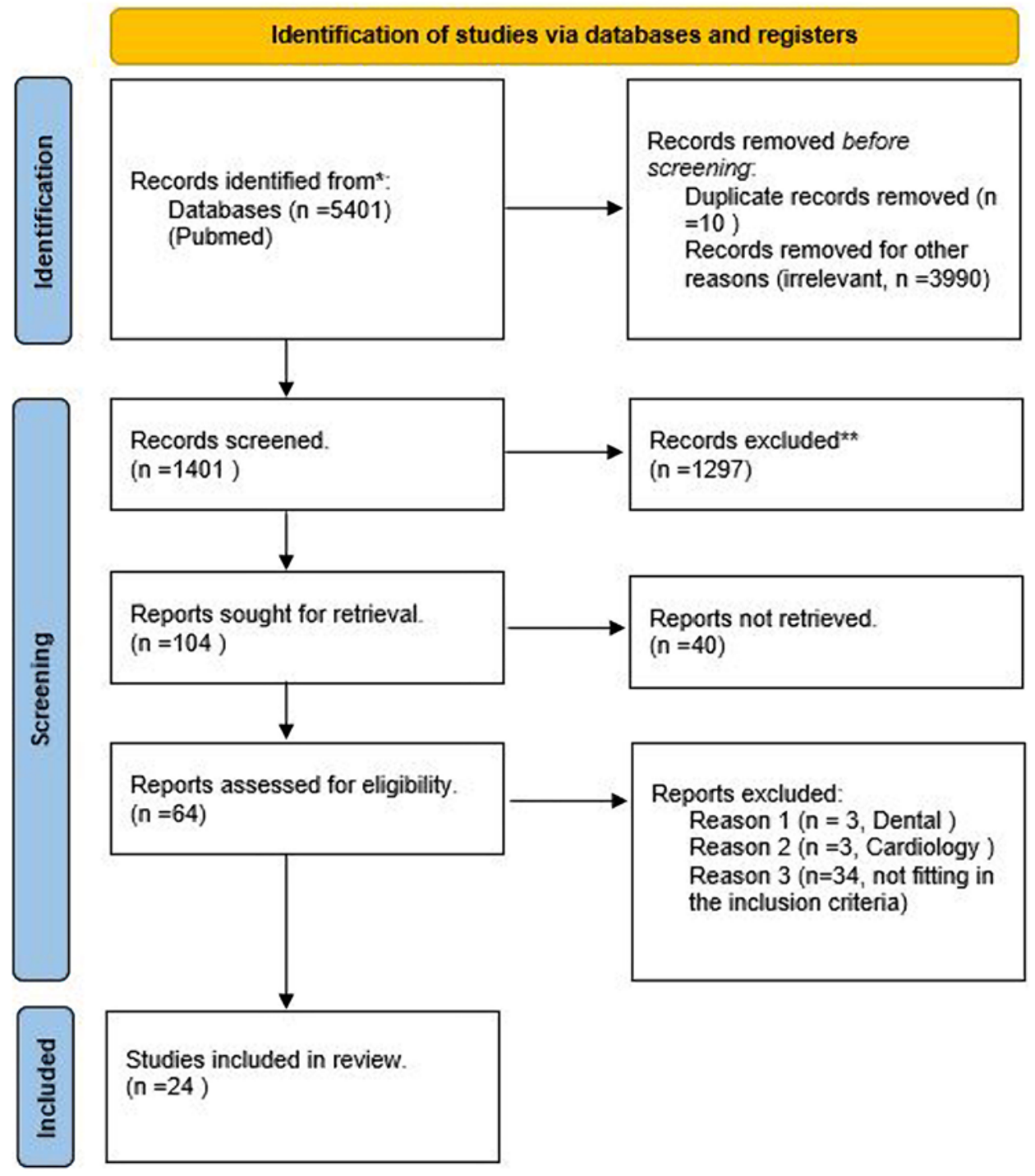

FIG. 1. PRISMA flowchart for systematic review of studies assessing the effect of postoperative telephone calls or text messages on patient satisfaction and/or safety. Data added to the PRISMA template (from Page MJ, McKenzie JE, Bossuyt PM, Boutron I, Hoffmann TC, Mulrow CD, et al. The PRISMA 2020 statement: an updated guideline for reporting systematic reviews. BMJ 2021;372:n71. doi: 10.1136/bmj.n71) under the terms of the Creative Commons Attribution License.

PubMed database was accessed on June 12, 2021, and queried for a literature search from January 2000 to June 2021. We did not register any systematic review protocol for the current review. The database was queried with the following term: ["post-operative" OR "surgical" OR "post-op" OR "surgery"] AND ["telephone" OR "phone" OR "call"]. Restrictions were applied to the English language. The literature search was performed by two authors (D.G. and J.A.K.). Any discrepancies between the article inclusion were resolved by mutual agreement. Risk for bias within the studies was assessed by using strict inclusion and exclusion criteria as well as dual review.

Following the literature search, all duplicates were excluded. The remaining articles were screened by title and the content of the abstract. The inclusion criteria for the articles were 1) surgical specialty, 2) $>50$ patients, 3) patient age $>18$ years, 4) published after 1999, 5) clinical trial or randomized controlled trial, 6) performance of an outpatient or inpatient surgical procedure, and 7) a telephone call or text message to patients within 3 months after the procedure.

\section{Patient Satisfaction or Safety Was Evaluated}

We excluded any systematic reviews and meta-analyses, non-English-language articles, dental specialties, pediatric series, and medical specialties. See Fig. 1 for the full PRISMA flowchart.

Outcomes sought within the literature review included patient satisfaction scores or survey results; patient safety data, including readmission rates, infection rates, and death; and patient outcomes after surgical intervention. 


\section{Results}

The search criteria revealed a total of 5401 articles. After excluding duplicate articles $(\mathrm{n}=10)$ and irrelevant articles, another 3990 articles were excluded. A total of 1401 articles were included for review of the abstract. After reviewing the abstract, a total of 64 relevant articles were found. The full text of these articles was reviewed. After applying the final inclusion criteria, 24 studies were included in the final analysis. Details of the included studies can be found in Table 1 .

Of 24 studies, only 2 were from neurosurgical specialties. The mean sample size of the studies was 181.97 patients (SD 258.91 patients). The mean patient age was 54.05 years (SD 12.89 years). Most studies were randomized controlled trials $(76.9 \%)$, and the remainder were prospective/clinical trials. The mean time frame for postoperative communication was 57.17 days (SD 89.12 days). The most common person making the telephone calls was the nurse $(41.7 \%)$, followed by the physician $(29.2 \%)$. The mean response rate was $89.8 \%$ (SD 11.3\%). Outpatient surgery was the most common type to use telephone follow-up (52.7\%). Patient satisfaction outcomes were measured in $43.4 \%$ of the studies. In the studies in which patient satisfaction was measured, most studies $(70 \%)$ reported that the telephone call follow-up was associated with higher patient satisfaction rates. Of the 24 studies included, 22 assessed patient safety and outcomes data. Of these, 11 found no difference in their primary outcomes, 11 found a positive effect from the telephone call, and no studies found a negative effect from the addition of a telephone call. Two of the studies were conducted within the neurosurgery specialty, and these were compared to the rest of the data (Table 2).

\section{Discussion}

In this systematic review of the literature, including all surgical specialties, we found that a postoperative telephone call improved patient satisfaction in most studies and enhanced patient safety or clinical outcome in half of the reviewed studies.

Several studies in this systematic review demonstrated increased patient satisfaction after implementation of a postoperative telephone call. For example, Caljouw and Hogendorf-Burgers implemented a nurse telephone call to outpatient gynecological surgery patients on postoperative days 3 through 9 and found a significant increase in patient satisfaction scores compared with patients who received standard care. ${ }^{22}$ Similar results were described following a laparoscopic appendectomy and cholecystectomy for patients who received a surgery resident call 2 weeks after surgery. ${ }^{13}$ Interestingly, in that study, the patients who received a call did not attend an in-person clinic follow-up. Although some might feel that losing face-to-face interaction could harm satisfaction scores, this study provides evidence that it may result in higher satisfaction.

Patient safety and outcomes in the postoperative period can be assessed clinically and through measures such as complication rates, use of emergency and urgent care facilities, and readmission rates. While different surgeries require different postoperative care, measuring outcomes through these measures can be a good standard to assess the quality of care in these areas. Our data revealed that 11 of 22 studies that assessed patient safety and outcomes positively changed from telephone call implementation. Carrier et al. found that the addition of a text message on days 1,3, and 5 after discharge to patients who underwent colorectal surgery versus standard care led to a decrease in patient-initiated contacts as well as detecting two early, potentially severe complications that eventually led to reoperation, thus improving patient safety. ${ }^{16}$ Postoperative telephone calls may also improve safety and outcomes by increasing compliance with postoperative directives. A study that investigated patients who underwent outpatient shoulder surgery and received a telephone call 3 times weekly for a month after surgery resulted in those patients in the call group having better adherence to prescribed physiotherapy and better range-of-motion outcomes. ${ }^{11}$

Overall, 11 of 22 studies that assessed patient safety and outcomes after the addition of a telephone call reported no significant difference in these measures. For instance, Thompson et al. described a trial comparing telephone call follow-up with standard care in patients who underwent pelvic surgery. ${ }^{10}$ The authors did not find any differences between the two groups in patient safety, outcomes, or satisfaction scores.

There are few drawbacks to implementing a postoperative call protocol to surgical practice, but increased patient care time and, by extension, expense are two to consider. There is also a question as to how closely patient satisfaction is linked to quality of care. Berkowitz et al. described the unclear relationship between Hospital Consumer Assessment of Healthcare Providers and Systems (HCAHPS) scores and quality of care. ${ }^{26}$ Patient satisfaction and safety are also directly tied to hospital reimbursement under the Affordable Care Act. ${ }^{27}$ Satisfaction scores can be influenced by expectations of care, communication with physician and staff, responsiveness of physician and staff, cleanliness, timeliness of telephone calls, appointments and results, and attire. ${ }^{28}$ Addressing the factors that healthcare providers can influence is a crucial first step in improving scores and perceived outcomes.

Postoperative telephone calls can be a potential liability if the call is improperly handled. In the case of Flanagan $v$ Southside Hospital, the plaintiff received a telephone call from her surgeon's office after an uneventful bilateral tubal ligation..$^{29}$ She was discharged the same day of surgery and the call was received the following day. She complained of abdominal pain, and the nurse making the call advised the patient to call her surgeon directly. The patient did not make a follow-up call and instead waited a few days until her symptoms sent her back to the hospital with an eventual bowel resection and colostomy. The plaintiff sued the surgeon, nurse, and hospital for lack of informed consent.

Decisions made in the Flanagan $v$ Southside Hospital case left $85 \%$ of the responsibility with the plaintiff as she did receive informed consent; however, $15 \%$ of the responsibility was placed on the nurse who made the telephone call. While the nurse did document that she urged the patient to contact the provider, the court concluded that it was the nurse's responsibility to inform the provider directly of the telephone encounter as she was not in a position to make decisions regarding the patient's care. Analysis of the case 
TABLE 1. Systematic review of postoperative telephone calls

\begin{tabular}{|c|c|c|c|c|c|c|c|c|c|c|c|}
\hline $\begin{array}{l}\text { Authors } \\
\& \text { Year }\end{array}$ & $\begin{array}{l}\text { RCT } \\
\text { vs } P\end{array}$ & $\begin{array}{l}\text { Surgical } \\
\text { Specialty }\end{array}$ & $\begin{array}{l}\text { Sample } \\
\text { Size }\end{array}$ & $\begin{array}{c}\text { Mean } \\
\text { Age (yrs) }\end{array}$ & $\begin{array}{l}\text { IP vs } \\
\text { OP }\end{array}$ & $\begin{array}{c}\text { Communication } \\
\text { Type }\end{array}$ & $\begin{array}{l}\text { Time } \\
\text { Frame }\end{array}$ & $\begin{array}{l}\text { Caller } \\
\text { Title }\end{array}$ & $\begin{array}{c}\text { Response } \\
\%\end{array}$ & Outcome & $\begin{array}{c}\mathrm{Pt} \\
\text { Satisfaction }\end{array}$ \\
\hline $\begin{array}{l}\text { Massoumi et al., } \\
2020^{4}\end{array}$ & $P$ & General & 276 & 18 & $\mathrm{OP}$ & $\mathrm{TC}$ & $\begin{array}{l}\text { Before } \\
\text { POD } 4\end{array}$ & MD & 100 & No difference & Not assessed \\
\hline Shah et al., $2021^{5}$ & $P$ & ENT & 83 & 58.8 & IP & TC & $\begin{array}{l}<72 \text { hrs } \\
\text { post-DC }\end{array}$ & MD & 91 & Fewer ED visits & Not assessed \\
\hline $\begin{array}{l}\text { Oestergaard et } \\
\text { al., } 2020^{6}\end{array}$ & RCT & NSGY & 41 & 40.5 & IP & $\mathrm{TC}$ & $\begin{array}{l}2,4,6, \& 10 \\
\text { wks postop }\end{array}$ & $\begin{array}{c}\text { Case } \\
\text { manager }\end{array}$ & 100 & No difference & Not assessed \\
\hline $\begin{array}{l}\text { Feldacker et al., } \\
2020^{7}\end{array}$ & RCT & Urology & 362 & 25 & OP & $\mathrm{TC}$ & $\begin{array}{l}\text { Daily } \times 14 \\
\text { days }\end{array}$ & Nurse & 92.5 & No difference & Not assessed \\
\hline $\begin{array}{l}\text { Taylan \& Akıl, } \\
2019^{8}\end{array}$ & RCT & General & 35 & 51 & IP & $\mathrm{TC}$ & $\begin{array}{c}1,2, \& 4 \\
\text { wks }\end{array}$ & $\begin{array}{l}\text { Coun- } \\
\text { selor }\end{array}$ & 100 & Not assessed & $\begin{array}{l}\text { Increased for } \\
\text { pts in call group }\end{array}$ \\
\hline Vance et al., $2019^{9}$ & RCT & Derm & 51 & 67 & OP & $\mathrm{TC}$ & POD 1 & MD & 100 & No difference & No difference \\
\hline $\begin{array}{l}\text { Thompson et al., } \\
2019^{10}\end{array}$ & RCT & OBGYN & 51 & 58 & $\mathrm{OP}$ & $\mathrm{TC}$ & $\begin{array}{c}2,6, \& 12 \\
\text { wks postop }\end{array}$ & Nurse & 96 & No difference & No difference \\
\hline $\begin{array}{l}\text { Martinez-Rico et } \\
\text { al., } 2018^{11}\end{array}$ & RCT & Ortho & 36 & 32 & $\mathrm{OP}$ & $\mathrm{TC}$ & $\begin{array}{c}\text { 3/wk for } 1 \\
\text { mo }\end{array}$ & Nurse & 100 & $\begin{array}{l}\text { Better ROM } \\
\text { outcomes }\end{array}$ & Not assessed \\
\hline $\begin{array}{l}\text { Iwanoff et al., } \\
2019^{12}\end{array}$ & $P$ & OBGYN & 233 & 59 & OP & $\mathrm{TC}$ & $\begin{array}{l}48-72 \mathrm{hrs} \\
\text { post-DC }\end{array}$ & MD & 100 & Not assessed & Not assessed \\
\hline Liu et al., $2019^{3}$ & $P$ & NSGY & 490 & 55 & IP & $\mathrm{TC}$ & $\begin{array}{l}48 \mathrm{hrs} \\
\text { postop }\end{array}$ & Nurse & 92 & $\begin{array}{l}\text { Decreased read- } \\
\text { mission rates }\end{array}$ & Not assessed \\
\hline Ma et al., $2018^{13}$ & RCT & General & 76 & 35 & OP & $\mathrm{TC}$ & $\begin{array}{l}2 \text { wks } \\
\text { postop }\end{array}$ & MD & 93 & No difference & $\begin{array}{l}\text { Increased } \\
\text { satisfaction }\end{array}$ \\
\hline $\begin{array}{l}\text { Szöts et al., } \\
2016^{14}\end{array}$ & RCT & Ortho & 59 & 67 & IP & $\mathrm{TC}$ & $\begin{array}{l}\text { PODs } 4 \\
\& 14\end{array}$ & NS & 97 & $\begin{array}{l}\text { Short-term } \\
\text { physical function } \\
\text { improvements }\end{array}$ & NS \\
\hline $\begin{array}{l}\text { Malmström et al., } \\
2016^{15}\end{array}$ & RCT & General & 41 & 64 & IP & $\mathrm{TC}$ & $\begin{array}{c}\text { 1/wk for } 2 \\
\text { mos }\end{array}$ & MD & 63 & No difference & $\begin{array}{l}\text { Increased } \\
\text { satisfaction }\end{array}$ \\
\hline $\begin{array}{l}\text { Kummerow Bro- } \\
\text { man et al., } 2016^{2}\end{array}$ & $P$ & General & 118 & 60 & OP & $\mathrm{TC}$ & POD 14 & PA & 88 & No difference & Not assessed \\
\hline $\begin{array}{l}\text { Carrier et al., } \\
2016^{16}\end{array}$ & $P$ & General & 111 & 53.5 & IP & Text & $\begin{array}{c}\text { Days } 1,3, \& \\
5 \text { post-DC }\end{array}$ & $\begin{array}{l}\text { Auto- } \\
\text { mated }\end{array}$ & 90 & Not assessed & $\begin{array}{l}\text { Increased } \\
\text { satisfaction }\end{array}$ \\
\hline $\begin{array}{l}\text { Palmen et al., } \\
2016^{17}\end{array}$ & RCT & Ortho & 24 & 50 & $\mathrm{OP}$ & $\mathrm{TC}$ & $\begin{array}{l}6 \text { mos } \\
\text { postop }\end{array}$ & MD & 79 & Not assessed & No difference \\
\hline Clari et al., $2015^{18}$ & RCT & Ortho & 110 & 47 & $\mathrm{OP}$ & $\mathrm{TC}$ & $\begin{array}{c}24-96 \mathrm{hrs} \\
\text { postop }\end{array}$ & Nurse & 80 & $\begin{array}{l}\text { Fewer postop } \\
\text { issues }\end{array}$ & Not assessed \\
\hline $\begin{array}{l}\text { Young et al., } \\
2013^{19}\end{array}$ & RCT & General & 387 & 68 & IP & $\mathrm{TC}$ & $\begin{array}{l}\text { PODs } 3 \\
\quad \& 10\end{array}$ & Nurse & 90 & No difference & Not assessed \\
\hline $\begin{array}{l}\text { Zhang et al., } \\
2013^{20}\end{array}$ & RCT & General & 59 & 53 & IP & $\mathrm{TC}$ & $\begin{array}{l}\text { PODs 3-7 } \\
\& 14-20\end{array}$ & Nurse & 88 & $\begin{array}{l}\text { Less complica- } \\
\text { tions }\end{array}$ & $\begin{array}{l}\text { Increased } \\
\text { satisfaction }\end{array}$ \\
\hline $\begin{array}{l}\text { Visser et al., } \\
2012^{21}\end{array}$ & RCT & Mixed & 1395 & 55 & Both & $\mathrm{TC}$ & POD 30 & NS & 64 & No difference & Not assessed \\
\hline $\begin{array}{l}\text { Caljouw \& } \\
\text { Hogendorf-Burg- } \\
\text { ers, } 2010^{22}\end{array}$ & RCT & OBGYN & 251 & 18 & IP & $\mathrm{TC}$ & PODs 3-9 & Nurse & 92 & No difference & $\begin{array}{l}\text { Increased } \\
\text { satisfaction }\end{array}$ \\
\hline $\begin{array}{l}\text { Kimman et al., } \\
2010^{23}\end{array}$ & RCT & General & 150 & 56 & IP & $\mathrm{TC}$ & $\begin{array}{c}3,6, \& 9 \\
\text { mos postop }\end{array}$ & Nurse & 100 & Not assessed & No difference \\
\hline $\begin{array}{l}\text { Hørdam et al., } \\
2010^{24}\end{array}$ & RCT & Ortho & 93 & 75 & IP & $\mathrm{TC}$ & $\begin{array}{c}4 \text { wks, } 3 \\
\text { mos, \& } 6 \\
\text { mos postop }\end{array}$ & Nurse & 70 & $\begin{array}{c}\text { Increased } \\
\text { health status }\end{array}$ & Not assessed \\
\hline $\begin{array}{l}\text { Tranmer \& Parry, } \\
2004^{25}\end{array}$ & RCT & Cardiac & 102 & 65 & IP & $\mathrm{TC}$ & $\begin{array}{l}\text { Weekly } \times 4 \\
\text { wks }\end{array}$ & NP & 89 & No difference & Not assessed \\
\hline
\end{tabular}

Cardiac = cardiothoracic surgery; $D C$ = discharge; derm = dermatology; ED = emergency department; ENT = otolaryngology; IP = inpatient; MD = medical doctor; NP = nurse practitioner; $\mathrm{NS}=$ not specified; $\mathrm{NSGY}=$ neurosurgery; $\mathrm{OBGYN}=$ obstetrics-gynecology; $\mathrm{OP}=$ outpatient; ortho = orthopedic surgery; $\mathrm{P}=$ prospective; $\mathrm{PA}=$ physician assistant; $\mathrm{pt}=$ patient; $\mathrm{POD}=$ postoperative day; $\mathrm{RCT}$ = randomized controlled trial; $\mathrm{ROM}=$ range of motion; $\mathrm{TC}=$ telephone call. 
reveals that the nurse could have been absolved of liability if she had simply explained the risks of not following up and criteria for emergency care and ensured that the patient knew it was her own decision from that point forward. ${ }^{30}$ Had the patient been uncertain, she would have erred on the side of safety by calling her gynecologist or returning to the hospital. If the patient decided not to, it would have been her decision and hers alone. Conversely, if the nurse had documented that she only clarified the discharge instructions and let the patient decide how to proceed, she would have been held equally liable as the plaintiff in this case.

An emerging form of communication, particularly in the era of COVID-19, is video conferencing through various telemedicine platforms. Use of telemedicine by spine surgeons has grown from $10 \%$ to more than $39 \%$ of all visits during the COVID-19 pandemic. ${ }^{31}$ Some studies have shown that telemedicine visits can be as effective as in-person visits in an orthopedic patient population. ${ }^{32}$ Although the cases of many neurosurgical patients may be more complicated and require in-person neurological examinations, postoperative telemedicine check-ins may prove to be a feasible option for routine procedures in uncomplicated cases. However, telemedicine technology is not without its problems. Up to $50 \%$ of telemedicine users have experienced technical difficulties during at least $15 \%$ of visits. ${ }^{31}$ When implemented correctly, however, it can be a useful adjunct to in-person visits while maintaining safety. A 2021 systematic review by $\mathrm{Ng}$ et al. found that surgical site infections could be diagnosed via telemedicine $70 \%$ to $100 \%$ of the time compared with in-person examinations. ${ }^{32}$ As telemedicine becomes more widely used, its feasibility and safety will become apparent.

\section{Limitations}

Our study has some significant limitations. The studies included were highly heterogeneous, precluding us from performing a meta-analysis. Due to the dearth of studies in the neurosurgical literature, we broadened our search to include all surgical specialties and recognize that outcomes may not be entirely generalizable. Although we felt that we had broad search criteria, it is possible that there may be some studies that were missed in this systematic review. Despite these limitations, we attempted to objectively study the impact of a postoperative telephone call on patient outcomes to evaluate whether implementation of such a practice may improve neurosurgical outcomes. Although we do not provide any novel data, we hope neurosurgeons will find this review of the available literature useful. In light of the pandemic, use of technology (telephone call or telemedicine) will soon become a standard practice across all specialties.

\section{Conclusions}

Postoperative telephone calls can provide meaningful change to patient satisfaction scores and patient safety and outcomes. While there is a paucity of data in the neurosurgical field, many other surgical specialties have found postoperative telephone calls to be beneficial. With strong evidence to support an increase in patient satisfaction, and some improvement in patient outcomes and safety, imple-
TABLE 2. Study characteristics compared between neurosurgery and all other specialties

\begin{tabular}{|c|c|c|c|}
\hline Variable & Neurosurgery & $\begin{array}{l}\text { Other Surgical } \\
\text { Specialties }\end{array}$ & $p$ Value \\
\hline \multicolumn{4}{|l|}{ Type of study, \% } \\
\hline RCT & 50 & 77.2 & \\
\hline Prospective & 50 & 22.9 & \\
\hline Mean sample size (SD) & $265.50(317.4)$ & $176(260.22)$ & 0.777 \\
\hline Mean age, yrs (SD) & $50.55(6.29)$ & $54.32(13.3)$ & 0.349 \\
\hline \multicolumn{4}{|l|}{ Type of op, $\%$} \\
\hline IP & 100 & 50.9 & \\
\hline OP & & 45.9 & \\
\hline Mixed & & 4.1 & \\
\hline \multicolumn{4}{|l|}{ Type of communication, \% } \\
\hline Phone call & 100 & 85.7 & \\
\hline Text message & & 7.1 & \\
\hline NA & & 7.1 & \\
\hline \multicolumn{4}{|l|}{ Time to contact, days } \\
\hline Mean (SD) & $36(48)$ & $47.86(82.59)$ & 0.802 \\
\hline Median & 36 & & \\
\hline \multicolumn{4}{|l|}{ Caller, \% } \\
\hline Physician & & 25 & \\
\hline Nurse & 50 & 37.5 & \\
\hline Other & 50 & 12.5 & \\
\hline Mean \% responders (SD) & $96(5.6)$ & $90.27(11.07)$ & 0.457 \\
\hline \multicolumn{4}{|l|}{$\begin{array}{l}\text { Patient satisfaction as- } \\
\text { sessment, \% }\end{array}$} \\
\hline Higher in pt call group & & 28.6 & \\
\hline No difference & & 10.7 & \\
\hline Not assessed & & 60.7 & \\
\hline
\end{tabular}

$\mathrm{NA}=$ not available.

mentation of a postoperative telephone call can be a simple way to impact neurosurgical patients in a positive manner.

\section{References}

1. Dewar A, Scott J, Muir J. Telephone follow-up for day surgery patients: patient perceptions and nurses' experiences. $J$ Perianesth Nurs. 2004;19(4):234-241.

2. Kummerow Broman K, Roumie CL, Stewart MK, Castellanos JA, Tarpley JL, Dittus RS, Pierce RA. Implementation of a telephone postoperative clinic in an integrated health system. J Am Coll Surg. 2016;223(4):644-651.

3. Liu J, Gormley N, Dasenbrock HH, Aglio LS, Smith TR, Gormley WB, Robertson FC. Cost-benefit analysis of transitional care in neurosurgery. Neurosurgery. 2019;85(5):672-679.

4. Massoumi RL, Crain N, Zhu C, Moore A, Oland G, Ghukasyan R, et al. Postoperative physician phone calls as a method to decrease urgent care and emergency department returns after ambulatory general surgery. Am Surg. 2020;86(10):1373-1378.

5. Shah M, Douglas J, Carey R, Daftari M, Smink T, Paisley A, et al. Reducing ER visits and readmissions after head and neck surgery through a phone-based quality improvement program. Ann Otol Rhinol Laryngol. 2021;130(1):24-31.

6. Oestergaard LG, Christensen FB, Bünger CE, Søgaard R, Holm R, Helmig P, Nielsen CV. Does adding case management to standard rehabilitation affect functional ability, pain, 
or the rate of return to work after lumbar spinal fusion? A randomized controlled trial with two-year follow-up. Clin Rehabil. 2020;34(3):357-368.

7. Feldacker C, Murenje V, Holeman I, Xaba S, MakunikeChikwinya B, Korir M, et al. Reducing provider workload while preserving patient safety: a randomized control trial using 2-way texting for postoperative follow-up in Zimbabwe's voluntary medical male circumcision program. $J$ Acquir Immune Defic Syndr. 2020;83(1):16-23.

8. Taylan S, Akıl Y. The effect of postoperative telephone counseling on the sexual life of patients with a bowel stoma: a randomized controlled trial. Wound Manag Prev. 2019;65(6):14-29.

9. Vance S, Fontecilla N, Samie FH, Patel V, Lewin JM. Effect of postoperative telephone calls on patient satisfaction and scar satisfaction after Mohs micrographic surgery. Dermatol Surg. 2019;45(12):1459-1464.

10. Thompson JC, Cichowski SB, Rogers RG, Qeadan F, Zambrano J, Wenzl C, et al. Outpatient visits versus telephone interviews for postoperative care: a randomized controlled trial. Int Urogynecol J Pelvic Floor Dysfunct. 2019;30(10):1639-1646.

11. Martinez-Rico S, Lizaur-Utrilla A, Sebastia-Forcada E, Vizcaya-Moreno MF, de Juan-Herrero J. The impact of a phone assistance nursing program on adherence to home exercises and final outcomes in patients who underwent shoulder instability surgery: a randomized controlled study. Orthop Nurs. 2018;37(6):372-378.

12. Iwanoff C, Giannopoulos M, Salamon C. Follow-up postoperative calls to reduce common postoperative complaints among urogynecology patients. Int Urogynecol J Pelvic Floor Dysfunct. 2019;30(10):1667-1672.

13. Ma Y, Jones G, Tay YK, Hunter T, Holden D, RodgersWilson S, et al. Post-operative telephone review is safe and effective: prospective study - Monash outpatient review by phone trial. ANZ J Surg. 2018;88(5):434-439.

14. Szöts K, Konradsen H, Solgaard S, Østergaard B. Telephone follow-up by nurse after total knee arthroplasty: results of a randomized clinical trial. Orthop Nurs. 2016;35(6):411-420.

15. Malmström M, Ivarsson B, Klefsgård R, Persson K, Jakobsson U, Johansson J. The effect of a nurse led telephone supportive care programme on patients' quality of life, received information and health care contacts after oesophageal cancer surgery-a six month RCT-follow-up study. Int $J$ Nurs Stud. 2016;64:86-95.

16. Carrier G, Cotte E, Beyer-Berjot L, Faucheron JL, Joris J, Slim K. Post-discharge follow-up using text messaging within an enhanced recovery program after colorectal surgery. $J$ Visc Surg. 2016;153(4):249-252.

17. Palmen LN, Schrier JC, Scholten R, Jansen JH, Koëter S. Is it too early to move to full electronic PROM data collection?: A randomized controlled trial comparing PROM's after hallux valgus captured by e-mail, traditional mail and telephone. Foot Ankle Surg. 2016;22(1):46-49.

18. Clari M, Frigerio S, Ricceri F, Pici A, Alvaro R, Dimonte V. Follow-up telephone calls to patients discharged after undergoing orthopaedic surgery: double-blind, randomised controlled trial of efficacy. J Clin Nurs. 2015;24(19-20):2736-2744.

19. Young JM, Butow PN, Walsh J, Durcinoska I, Dobbins TA, Rodwell L, et al. Multicenter randomized trial of centralized nurse-led telephone-based care coordination to improve outcomes after surgical resection for colorectal cancer: the CONNECT intervention. J Clin Oncol. 2013;31(28):3585-3591.

20. Zhang JE, Wong FK, You LM, Zheng MC, Li Q, Zhang BY, et al. Effects of enterostomal nurse telephone follow-up on postoperative adjustment of discharged colostomy patients. Cancer Nurs. 2013;36(6):419-428.

21. Visser A, Ubbink DT, Gouma DJ, Goslings JC. Questionnaire versus telephone follow-up to detect postdischarge complications in surgical patients: randomized clinical trial. World J Surg. 2012;36(11):2576-2583.
22. Caljouw MA, Hogendorf-Burgers ME. GYNOTEL: telephone advice to gynaecological surgical patients after discharge. J Clin Nurs. 2010;19(23-24):3301-3306.

23. Kimman ML, Bloebaum MM, Dirksen CD, Houben RM, Lambin P, Boersma LJ. Patient satisfaction with nurse-led telephone follow-up after curative treatment for breast cancer. BMC Cancer. 2010;10:174.

24. Hørdam B, Sabroe S, Pedersen PU, Mejdahl S, Søballe K. Nursing intervention by telephone interviews of patients aged over 65 years after total hip replacement improves health status: a randomised clinical trial. Scand J Caring Sci. 2010;24(1):94-100.

25. Tranmer JE, Parry MJ. Enhancing postoperative recovery of cardiac surgery patients: a randomized clinical trial of an advanced practice nursing intervention. West J Nurs Res. 2004; 26(5):515-532.

26. Berkowitz R, Vu J, Brummett C, Waljee J, Englesbe M, Howard R. The impact of complications and pain on patient satisfaction. Ann Surg. 2021;273(6):1127-1134.

27. Stanowski AC, Simpson K, White A. Pay for performance: are hospitals becoming more efficient in improving their patient experience? J Healthc Manag. 2015;60(4):268-285.

28. Eisenburg A. What is patient satisfaction and why does it matter? Wolters Kluwer Expert Insights. June 18, 2020. Accessed September 8, 2021. https://www.wolterskluwer.com/en/expertinsights/what-is-patient-satisfaction-and-why-does-it-matter

29. Flanagan v Southside Hospital, 251 AD2d 447674 NYS672d 723 (NY App Div 1998).

30. Lyddane J. Legal Update - Legal liability in post-discharge phone calls. Outpatient Surgery. June 3, 2013. Accessed September 8, 2021. https://www.aorn.org/outpatient-surgery/ articles/outpatient-surgery-magazine/2013/june/legal-updatelegal-liability-in-post-discharge-phone-calls

31. Riew GJ, Lovecchio F, Samartzis D, Louie PK, Germscheid N, An H, et al. Telemedicine in spine surgery: global perspectives and practices. Global Spine J. Published online June 14, 2021. doi:10.1177/21925682211022311

32. Ng HJH, Huang D, Rajaratnam V. Diagnosing surgical site infections using telemedicine: a systematic review. Surgeon. Published online June 19, 2021. doi:10.1016/j.surge.2021.05.004

\section{Disclaimer}

The views expressed in this article reflect the results of research conducted by the authors and do not necessarily reflect the official policy or position of the Department of the Navy, Department of Defense, or the United States Government. Neither the Department of the Navy nor any other component of the Department of Defense has approved, endorsed, or authorized this article.

\section{Disclosures}

The authors report no conflict of interest concerning the materials or methods used in this study or the findings specified in this paper.

\section{Author Contributions}

Conception and design: Goehner, Kosty. Acquisition of data: Goehner, Kosty. Analysis and interpretation of data: Goehner, Kandregula, Birk. Drafting the article: Goehner, Kandregula, Birk. Critically revising the article: Guthikonda, Goehner, Carroll, Kosty. Reviewed submitted version of manuscript: Guthikonda, Goehner, Carroll, Kosty. Statistical analysis: Goehner, Kandregula, Birk. Administrative/technical/material support: Goehner. Study supervision: Kosty.

\section{Correspondence}

Bharat Guthikonda: Louisiana State University Health Shreveport School of Medicine, Shreveport, LA. bguthi@lsuhsc.edu. 